\title{
Polymorphisms in metabolic genes, their combination and interaction with tobacco smoke and alcohol consumption and risk of gastric cancer: a case-control study in an Italian population
} Stefania Boccia*1, Fakhredin A Sayed-Tabatabaei², Roberto Persiani ${ }^{3}$, Francesco Gianfagna ${ }^{1}$, Stefano Rausei ${ }^{3}$, Dario Arzani ${ }^{1}$, Antonio La Greca ${ }^{3}$, Domenico D'Ugo ${ }^{3}$, Giuseppe La Torre ${ }^{1}$, Cornelia M van Duijn ${ }^{4}$ and Gualtiero Ricciardi ${ }^{1}$

Address: ${ }^{1}$ Genetic Epidemiology and Molecular Biology Unit, Institute of Hygiene, Università Cattolica del Sacro Cuore, Rome, Italy, ${ }^{2} \mathrm{Medicines}$ Evaluation Board Agency, The Hague, The Netherlands, ${ }^{3}$ Department of Surgery, Università Cattolica del Sacro Cuore, Rome, Italy and ${ }^{4}$ Department of Epidemiology \& Biostatistics, Erasmus Medical Center, Rotterdam, The Netherlands

Email: Stefania Boccia* - sboccia@rm.unicatt.it; Fakhredin A Sayed-Tabatabaei - fakhredin@gmail.com;

Roberto Persiani - rpersiani@rm.unicatt.it; Francesco Gianfagna - francescogianfagna@yahoo.it; Stefano Rausei - s.rausei@libero.it; Dario Arzani - dario.arzani@rm.unicatt.it; Antonio La Greca - antonio.lagreca@rm.unicatt.it; Domenico D'Ugo - ddugo@rm.unicatt.it; Giuseppe La Torre - giuseppe.latorre@rm.unicatt.it; Cornelia M van Duijn - c.vanduijn@erasmusmc.nl;

Gualtiero Ricciardi - wricciardi@rm.unicatt.it

* Corresponding author

Published: 8 November 2007

BMC Cancer 2007, 7:206 doi:10.1186/147|-2407-7-206
Received: 17 July 2007

Accepted: 8 November 2007

This article is available from: http://www.biomedcentral.com/I47/-2407/7/206

(c) 2007 Boccia et al; licensee BioMed Central Ltd.

This is an Open Access article distributed under the terms of the Creative Commons Attribution License (http://creativecommons.org/licenses/by/2.0), which permits unrestricted use, distribution, and reproduction in any medium, provided the original work is properly cited.

\begin{abstract}
Background: The distribution and the potential gene-gene and gene-environment interaction of selected metabolic genetic polymorphisms was investigated in relation to gastric cancer risk in an Italian population.

Methods: One hundred and seven cases and 254 hospital controls, matched by age and gender, were genotyped for CYPIAI, CYP2EI, mEH, GSTMI, GSTTI, NAT2 and SULTIAI polymorphisms. Haplotype analysis was performed for EPHXI exons 3 and 4 , as well as CYP2EI Rsal (*5 alleles) and CYP2EI Dral (*5A or *6 alleles). The effect modification by alcohol and cigarette smoking was tested with the heterogeneity test, while the attributable proportion (AP) was used to measure the biological interaction from the gene-gene interaction analysis.

Results: Gastric cancer risk was found to be associated with the inheritance of GSTTI null genotype $(\mathrm{OR}=2.10,95 \% \mathrm{Cl}: 1.27-3.44)$ and the SULTIAI His/His genotype $(\mathrm{OR}=2.46,95 \% \mathrm{Cl}$ : 1.03-5.90). No differences were observed for the haplotype distributions among cases and controls. For the first time an increased risk was detected among individuals carrying the *6 variant allele of CYP2EI if ever-drinkers (OR $=3.70 ; 95 \% \mathrm{Cl}$ : I.45-9.37) with respect to never-drinkers (OR $=0.18 ; 95 \% \mathrm{Cl}: 0.22-\mathrm{I} .46)$ ( $\mathrm{p}$ value of heterogeneity among the two estimates $=0.00 \mathrm{I}$ ). Similarly, the effect of SULTIAI variant genotype resulted restricted to ever-smokers, with an OR of 2.58 (95\% Cl: I.27-5.25) for the carriers of His allele among smokers, and an OR of 0.86 ( $95 \% \mathrm{Cl}$ : $0.45-$ I.64) among never-smokers ( $p$ value of heterogeneity among the two estimates $=0.03$ ). The genegene interaction analyses demonstrated that individuals with combined GSTTI null and NAT2 slow
\end{abstract}


acetylators had an additional increased risk of gastric cancer, with an OR of 3.00 (95\% Cl: I.52-5.93) and an $\mathrm{AP}$ of $52 \%$.

Conclusion: GSTTI, SULTIAI and NAT2 polymorphisms appear to modulate individual's susceptibility to gastric cancer in this Italian population, particularly when more than one unfavourable genotype is present, or when combined with cigarette smoke. The increased risk for the carriers of CYP2EI*5A or *6 alleles among drinkers need to be confirmed by larger prospective studies.

\section{Background}

Gastric cancer is the second most common cause of mortality from cancer, with 647,000 deaths reported worldwide in 2002 [1]. In many populations, particularly in high-income countries, in the last decades its incidence has gradually decreased, however it still represents the fifth most common type of cancer in Europe and the fourth internationally [1]. The development of gastric cancer appears to be the result of a complex interaction between lifestyle and genetic factors. Among the lifestyle and related risk factors, Helicobacter pylori infection, tobacco smoking, a high intake of salt and lack of food refrigeration all seem to play a major role [2]. Additionally, gastric cancer shows a familial clustering [3]. With regards to genetic factors, several Single Nucleotide Polymorphisms (SNPs) might potentially alter the individual susceptibility to gastric cancer, among them genes coding for metabolic enzymes [4].

A major part of carcinogenic substances require metabolic activation by enzymes to be genotoxic, and inherited variations in carcinogens metabolizing genes may alter enzyme activity and subsequently carcinogens activation or deactivation. Phase I enzymes, including Cytochrome P450 (CYP) and microsomal Epoxide Hydrolase (mEH), activate several compounds to form genotoxic electrophilic intermediates. Activated metabolites are then, in part, detoxified by phase II enzymes, such as glutathione S-transferase (GST), N-acetyltransferase (NAT) and Sulfotransferase (SULT) [5]. We recently showed, for the first time, that SULT1A1 Arg213His polymorphism might affect the risk of gastric cancer [6], while contradictory results concerning several SNPs in metabolic genes have been reported [7-15].

Based on the knowledge that metabolic genes are presumed to modulate an individual's susceptibility to cancer by interacting with carcinogens, and since the inheritance of several unfavourable genotypes is supposed to additionally increase the risk of gastric cancer $[8,9,11]$, this hospital-based case-control study aims to investigate the effect on gastric cancer of selected SNPs of CYP1A1, CYP2E1, mEH, GSTM1, GSTT1, NAT2, SULT1A1, and their differential effect according to tobacco smoking and alcohol habits. We also investigated to what extent the inher- itance of more than one unfavourable genotype affects the risk of gastric cancer.

\section{Methods \\ Study population}

The study subjects were selected according to a case-control study design as previously described [16]. Briefly, cases were consecutive primary gastric adenocarcinoma patients, with histological confirmation, who underwent a curative gastrectomy in the "A. Gemelli" teaching hospital, located within the Università Cattolica del Sacro Cuore in Rome. We defined gastric cancer cases as including International Classification of Disease Ninth revision codes 151.0-151.9. Controls were selected from cancerfree patients, with a broad range of diagnoses including around $15 \%$ of blood donors, admitted to the same hospital during the identical time period and were frequency matched to cases for age ( \pm 5 years) and gender. All subjects were Caucasians born in Italy. According to the Lauren histotype classification [17], the majority (57.8\%) of the gastric cancer cases were intestinal. The tumours were located in the antrum $(39.3 \%)$, in the corpus $(14.8 \%)$, in the antrum/corpus $(28.0 \%)$, in the cardia $(10.3 \%)$, stumps $(5.6 \%)$ and in the fundum $(2.0 \%)$. Based on the cytological and architectural atypisms, as well as the histopathological reports [18], patients' tumours were classified accordingly: $68.3 \%$ scarcely differentiated, $29.2 \%$ moderately differentiated, $2.5 \%$ well-differentiated, while $53.8 \%$ were staged I-II and $46.2 \%$ staged III-IV. With a response rate of $95 \%$ and $90 \%$ respectively for cases and controls, 102 gastric cancer and 254 controls were recruited.

A venous blood sample was drawn from each participant, collected into an EDTA-coated tubes from which DNA was isolated from peripheral blood lymphocytes. The study was approved by the local review board and written informed consent was obtained from each subject. The procedures followed were in accordance with the Helsinki Declaration.

\section{Data collection}

Cases and controls were interviewed by trained medical doctors using a standard questionnaire to elicit information on demographic variables, tobacco smoking (includ- 
ing cigarette, cigar and pipe) and drinking history, dietary habits and family history of cancer. Questions pertaining to lifestyle focused on the time period ending one year prior to diagnosis. Smoking status was categorized as never and ever-smokers (including both current and former smokers) and alcohol consumption as drinkers/ non-drinkers (the latter including individuals whose alcohol intake less than $7 \mathrm{~g} /$ day). Fruit and vegetables intake was classified as high if the participant consumed at least two portions of fruit and two portions of vegetables per day. Meals salt addition was referred to the use of adding salt to the entrées during the main meals. Family history (including non-melanoma skin cancer) of cancer referred to parents, siblings and offspring. Data concerning previous Helicobacter pylori infection was not available for either cases or controls. The response rate for completing the interview was $99.1 \%$ for cases (106/107) and 99.6\% (253/254) for controls, with the exception of data relating to a family history of cancer [unknown in $7.4 \%(8 / 107)$ of cases and 3.5\% (9/254) of controls].

\section{Genotyping}

GSTM1 and GSTT1 null alleles were identified using a multiplex-Polymerase Chain Reaction (PCR)-based method as described by Arand et al. [19]. The polymorphic site at nucleotide 638 in exon 7 (Arg213His) of the SULT1A1 gene was genotyped by PCR-Restriction Fragment Length Polymorphisms (RFLP) analysis as described by Coughtrie et al. [20]. Identification of the $m E H$ exon 3 (Tyr113His) and exon 4 (His139Arg) polymorphisms was performed using a RFLP-based method [21]. CYP1A1 3'flanking region MspI polymorphism (CYP1A $1 * 2 A$ allele), CYP2E1 RsaI polymorphism (CYP2E1*5 alleles) and CYP2E1 DraI ( ${ }^{*} 5 A$ or ${ }^{*} 6$ alleles) were also determined by PCR-RFLP analyses (21). Three known slow acetylator alleles, NAT2*5A, *6A and *7A were identified as previously described by Peluso et al [22]. Fast acetylator genotypes are the homo-heterozyogous wild-type alleles $\left({ }^{*} 4 \mathrm{~A}\right)$, slow acetylator genotypes are those with 2 slow acetylator alleles [23]. Quality control for each genotyping was performed in each experiment, and $10 \%$ of the total samples were randomly selected and reanalyzed with $100 \%$ concordance. The analyst was blinded to the case or control status of the samples.

\section{Statistical analysis}

The relationship between gastric cancer and putative risk factors were measured using the adjusted odds ratios (ORs) and their 95\% CI derived from logistic regression analysis using STATA software (version 8.2). We considered possible risk factors for gastric cancer as potential confounders if the addition of that variable to the model changed the OR by $10 \%$ or greater. Confounding checks were performed in both of the univariate and final multivariate models. If a factor was identified as a confounder of any estimated main effect, it was kept in all models. Based on these criteria, we controlled for age, gender, alcohol consumption and family history of cancer, when appropriate. In the multivariable model, we adjusted for the continuous variables of age and alcohol (g/day).

The genotypes of GSTM1 and GSTT1 were dichotomized according to the presence versus absence of the null allele, and NAT2 was dichotomized according to the inferred phenotype (slow versus fast). We analyzed exon 3 and exon $4 \mathrm{mEH}$ genotypes by "imputed phenotype" as suggested from Smith and Harrison [24]. Lastly, we conducted haplotype analysis for EPHX1 exons 3 and 4, as well as CYP2E1*5 and ${ }^{*} 5 \mathrm{~A}$ or ${ }^{*} 6$ using Cocaphase software. Hardy-Weinberg Equilibrium (HWE) was tested for separately all of the case and control SNPs.

In order to assess if the effect of the studied polymorphisms is modified by tobacco smoking and alcohol consumption, we performed a stratified logistic regression analysis. An heterogeneity test was then used to test differences among the strata.

Biological interaction between two genes was estimated using departure from additivity of effects as the criterion of interaction, as suggested by Rothman [25]. To quantify the amount of interaction, the attributable proportion (AP) due to interaction was calculated as described by Andersson et al [26]. The AP due to interaction is the proportion of individuals among those exposed to the two interacting factors that is attributable to the interaction per se and it is equal to 0 in the absence of a biological interaction [25]. Finally, in order to test for more than multiplicative effect among two genes, the likelihood ratio test was used, with the homozygous wild-type individuals for both genes as the reference group.

\section{Results}

General characteristics of the study population are presented in Table 1. Alcohol consumption and family history of cancer were associated with an increased risk of gastric cancer, with ORs of 2.10 (95\% CI: 1.22-3.60) and an OR of 1.93 (95\%CI: 1.14-3.26), respectively (Table 1). The genotype frequencies of our control group were in line with those for Caucasians and were in HWE both for cases and controls $(p>0.05)[5,20]$. As shown in Table 2, we found a significant difference in the distribution of GSTT1 null and SULT1A1 His/His genotype amongst cases and controls: $37.1 \%$ versus $22.4 \%(\mathrm{OR}=2.10,95 \%$ CI: $1.27-3.44)$ and $10.3 \%$ versus $5.1 \%(\mathrm{OR}=2.46 ; 95 \%$ CI: 1.03-5.90), respectively. An increased risk was also detected for NAT2 slow acetylators $(\mathrm{OR}=1.38,95 \% \mathrm{CI}$ : $0.88-2.19$ ), however not statistically significant. Haplotype analyses indicated that there was no significant linkage disequilibrium between EPHX1 exons 3 and 4, as well 
Table I: Odds Ratios $(95 \% \mathrm{Cl})$ of gastric cancer according to the collected variables and their frequency distribution among 107 cases and 254 controls

\begin{tabular}{|c|c|c|c|}
\hline & Cases \% (n) & Controls \% (n) & OR $(95 \% \mathrm{Cl}) \dagger$ \\
\hline Age (years $\pm S D)$ & $66.4 \pm 12.0$ & $64.0 \pm 12.8$ & - \\
\hline Male gender & $52.3(56)$ & $55.5(14 I)$ & - \\
\hline \multicolumn{4}{|l|}{ Alcohol drinkers } \\
\hline Non-drinkers ${ }^{\circ}$ & $29.9(32)$ & $47.6(121)$ & $\mathbf{I}^{*}$ \\
\hline Drinkers & 70.1 (73) & $52.4(133)$ & $2.10(1.22-3.60)$ \\
\hline \multicolumn{4}{|l|}{ Smoking status } \\
\hline Never & $53.3(57)$ & $57.5(146)$ & $I^{*}$ \\
\hline Ever & $46.7(50)$ & $42.5(108)$ & $1.10(0.64-1.90)$ \\
\hline \multicolumn{4}{|c|}{ Fruit and vegetables intake } \\
\hline High $\ddagger$ & $20.0(2 \mathrm{I})$ & $15.8(40)$ & $I^{*}$ \\
\hline Low & $80.2(85)$ & $84.2(2 \mid 3)$ & $0.95(0.50-1.90)$ \\
\hline \multicolumn{4}{|l|}{ Grilled meat } \\
\hline$\leq 2$ times/month & $52.3(56)$ & $48.4(123)$ & $I^{*}$ \\
\hline$>2$ times/month & $47.7(61)$ & $51.6(131)$ & $0.99(0.60-1.66)$ \\
\hline \multicolumn{4}{|l|}{ Meals salt addition^^} \\
\hline No & $85.1(91)$ & $92.9(235)$ & $I^{*}$ \\
\hline Yes & $14.9(16)$ & $7.1(18)$ & $1.70(0.78-3.67)$ \\
\hline \multicolumn{4}{|l|}{ Familiarity for cancer } \\
\hline No & $61.6(61)$ & $78.4(192)$ & $I^{*}$ \\
\hline Yes & $38.4(38)$ & $21.6(53)$ & $1.93(1.14-3.26)$ \\
\hline \multicolumn{4}{|c|}{ Familiarity for gastric cancer } \\
\hline No & $88.0(88)$ & $94.4(237)$ & I* \\
\hline Yes & $12.0(12)$ & $5.6(14)$ & $1.88(0.80-4.44)$ \\
\hline
\end{tabular}

* Reference category; † OR adjusted for age, gender, alcohol consumption and familiarity for cancer; $\ddagger$ High fruit and vegetables consumption is defined as at least 2 portions of fruit and 2 portions of vegetables per day; ${ }^{\circ}$ Non-drinkers defined as an alcohol intake less than $7 \mathrm{~g} / \mathrm{day} ;{ }^{\wedge}$ adding salt to the entrées during the main meals

Table 2: Odds Ratios $(95 \% \mathrm{Cl})$ of gastric cancer for SNPs in metabolic genes and their frequency distribution among 107 cases and 254 controls

\begin{tabular}{|c|c|c|c|c|}
\hline & & Cases \% (n) & Controls \% (n) & OR $(95 \% \mathrm{Cl}) * \dagger$ \\
\hline GSTMI null & & $56.2(59)$ & $52.7(135)$ & $1.13(0.71-1.79)$ \\
\hline GSTTI null & & 37.1 (39) & $22.4(57)$ & $2.10(1.27-3.44)$ \\
\hline CYPIAI $* 2 A$ & & $20.5(22)$ & $22.0(56)$ & $0.88(0.50-1.54)$ \\
\hline CYP2EI*5 & & $4.7(5)$ & $7.8(20)$ & $0.54(0.20-1.50)$ \\
\hline CYP2EI*5A or $* 6$ & & $14.5(15)$ & $10.6(27)$ & $1.33(0.67-2.65)$ \\
\hline NAT2 Slow $\ddagger$ & & $59.8(64)$ & $51.8(131)$ & I. $38(0.88-2.19)$ \\
\hline \multirow[t]{2}{*}{ SULTIAI } & Arg/His & $36.5(39)$ & $33.5(85)$ & $1.35(0.82-2.21)$ \\
\hline & $\mathrm{His} / \mathrm{His}$ & $10.3(11)$ & $5.1(13)$ & $2.46(1.03-5.90)$ \\
\hline \multirow[t]{2}{*}{$E P H X I$ exon 3} & Tyr/His & $38.7(4 I)$ & $36.0(90)$ & $1.24(0.76-2.04)$ \\
\hline & His/His & $14.1(15)$ & $11.2(28)$ & $1.37(0.67-2.80)$ \\
\hline \multirow[t]{2}{*}{$E P H X 4$ exon 4} & His/Arg & $30.5(32)$ & $37.4(95)$ & $0.77(0.47-1.27)$ \\
\hline & Arg/Arg & $5.7(6)$ & $2.4(6)$ & $2.28(0.70-7.20)$ \\
\hline \multirow[t]{3}{*}{ Imputed $m E H$ phenotypes ${ }^{\wedge}$} & Rapid & $15.8(15)$ & $23.7(59)$ & $0.60(0.30-1.15)$ \\
\hline & Slow & $25.3(24)$ & $21.2(54)$ & $1.00(0.55-1.78)$ \\
\hline & Very slow & $8.4(8)$ & $8.6(2 I)$ & $0.82(0.33-2.00)$ \\
\hline
\end{tabular}

* OR adjusted for age and gender

† Reference groups are the homozygous wild genotypes for each gene

$\ddagger$ Reference group is fast acetylators (homo-heterozygous for the wild-type allele)

$\wedge$ Reference group is the normal imputed phenotype 
as CYP2E1*5 and ${ }^{*} 5 A$ or ${ }^{*} 6$, amongst the cases and the controls. Furthermore, the frequency of the estimated haplotypes was the same among the groups (data not shown).

From the stratified analysis according to smoking status (Table 3), the significant association for SULT1A1 observed in the overall analysis seems to be limited to ever smokers, with a $p$ value for heterogeneity among the two strata of 0.03 (Table 3). On the other hand, the increased risk for GSTT1 null individuals was significant regardless of the smoking status (Table 3). As for the effect modification by alcohol habits, drinking subjects carrying the variant allele of CYP2E1 ( ${ }^{*} 5 A$ or ${ }^{*} 6$ alleles) had an OR of 3.70 (95\%CI: $1.45-9.37$ ) of gastric cancer compared to those drinking without the variant allele, with the result of the heterogeneity test among the strata showing a significant effect modification by alcohol ( $p$ value $=0.001$, Table 3).

To reduce the chance of multiple testing, we limited the gene-gene interaction analyses to the three SNPs that exhibited the most prominent association with gastric cancer. It was observed that in all of the combinations individuals carrying two risk genotypes had an additional risk compared to those with only one risk genotype, with an $\mathrm{AP}$ greater than 0 , however there was no evidence of multiplicative interaction ( $p$ values $>0.05$, Table 4 ). The observed effect was particularly high amongst individuals with both GSTT1 null and NAT2 slow (OR = 3.00, 95\% CI: 1.52-5.93; AP = 52\%) (Table 4). Additionally, by stratifying these data according to smoking status (data not shown), ever-smoker individuals with combined GSTT1 null and NAT2 slow had an OR of 4.23 (95\% CI: 1.4912.01) compared to ever-smokers with combined normal variants, while an OR of 2.60 (95\% CI: 1.00-6.67) appeared using the same comparators amongst neversmokers ( $p$ value of heterogeneity among the two estimates $=0.49)$.

\section{Discussion}

This case-control study of 107 surgical cases of gastric adenocarcinoma and 254 controls born in Italy evaluated the effect on gastric cancer risk of several metabolic gene polymorphisms simultaneously. Results showed a significantly increased risk for GSTT1 null and for SULT1A1 homozygotes, and an additional risk for NAT2 slow acetylator individuals, although not statistically significant. Risks associated with those genes became substantive when two unfavourable genotypes were combined, with evidence of biological interaction between them. From the gene-environment interaction analysis, we showed effect modification of the association between SULT1A1 and gastric cancer by tobacco smoking, and

Table 3: Odds Ratios $(95 \% \mathrm{Cl})$ of gastric cancer for SNPs in metabolic genes according to smoking status and alcohol habits

\begin{tabular}{|c|c|c|c|c|c|}
\hline & \multicolumn{2}{|c|}{ Never-smokers (57 cases, I46 controls) } & \multicolumn{2}{|c|}{ Ever-smokers (50 cases, 108 controls) } & \multirow[t]{2}{*}{$p$ for heterogeneity } \\
\hline & cases/controls & OR $(95 \% \mathrm{Cl}) * \dagger$ & cases/controls & OR $(95 \% \mathrm{Cl})$ & \\
\hline GSTM I null & $33 / 70$ & $1.55(0.83-2.90)$ & $26 / 64$ & $0.70(0.35-1.39)$ & 0.10 \\
\hline GSTTI null & $21 / 34$ & $2.09(1.06-4.11)$ & $18 / 23$ & $2.17(1.02-4.59)$ & 0.92 \\
\hline$C Y P I A I * 2 A$ & $14 / 33$ & 1.09 (0.53-2.27) & $8 / 23$ & $0.66(0.27-I .6 I)$ & 0.40 \\
\hline CYP2EI*5 & $4 / 11$ & $0.86(0.26-2.88)$ & $1 / 9$ & $0.20(0.02-2.70)$ & 0.24 \\
\hline CYP2EI*5A or *6 & $10 / 17$ & $1.59(0.67-3.79)$ & $5 / 10$ & $0.99(0.31-3.13)$ & 0.58 \\
\hline NAT2 Slow $\ddagger$ & $34 / 77$ & $1.39(0.74-2.60)$ & $30 / 54$ & $1.50(0.75-2.98)$ & 0.87 \\
\hline SULTIAI His carriers & $22 / 62$ & $0.86(0.45-1.64)$ & $27 / 36$ & $2.58(1.27-5.25)$ & 0.03 \\
\hline $\begin{array}{l}\text { EPHXI exon } 3 \text { His } \\
\text { carriers }\end{array}$ & $28 / 62$ & I.3I (0.70-2.46) & $28 / 56$ & $1.12(0.57-2.22)$ & 0.69 \\
\hline \multirow{3}{*}{$\begin{array}{l}\text { EPHX } 4 \text { exon } 4 \text { Arg } \\
\text { carriers }\end{array}$} & $21 / 63$ & $0.84(0.44-1.60)$ & $16 / 38$ & $0.89(0.43-1.85)$ & 0.85 \\
\hline & \multicolumn{2}{|c|}{ Never-drinkers (32 cases, 121 controls) } & \multicolumn{2}{|c|}{ Ever-drinkers (73 cases, I 33 controls) } & $p$ for heterogeneity \\
\hline & cases/controls & OR $(95 \% \mathrm{Cl})$ & cases/controls & OR $(95 \% \mathrm{Cl})$ & \\
\hline GSTM I null & $16 / 64$ & $0.95(0.43-2.10)$ & $43 / 70$ & $1.23(0.69-2.20)$ & 0.55 \\
\hline GSTTI null & $13 / 24$ & $3.15(1.32-7.47)$ & $26 / 33$ & $1.72(0.92-3.22)$ & 0.27 \\
\hline CYP2EI*5 & $0 / 10$ & - & $5 / 10$ & $0.86(0.28-2.68)$ & - \\
\hline CYP $2 E I * 5 A$ or $* 6$ & $1 / 19$ & $0.18(0.22-1.46)$ & $14 / 8$ & $3.70(1.45-9.37)$ & 0.001 \\
\hline SULTIA I His carriers & $|6 / 5|$ & $1.42(0.63-3.17)$ & $33 / 47$ & $1.56(0.86-2.82)$ & 0.98 \\
\hline
\end{tabular}

* OR adjusted for age and gender

† Reference groups are the homozygous wild genotypes for each gene

$\ddagger$ Reference group is fast acetylators (homo-heterozygous for the wild-type allele) 
Table 4: Age and gender adjusted Odds Ratios $(95 \% \mathrm{Cl})$ of gastric cancer for selected gene-gene interaction analyses

\begin{tabular}{|c|c|c|c|c|c|}
\hline & & \multicolumn{2}{|c|}{ GSTTI } & \multicolumn{2}{|c|}{ SULTIAI } \\
\hline & & Present & Null & Arg/Arg & His car. \\
\hline \multirow[t]{5}{*}{ NAT2 } & Fast & $I^{*}$ & I. $38(0.63-3.01)$ & $I^{*}$ & $1.45(0.7 \mathrm{I}-2.95)$ \\
\hline & cases/controls & $30 / 93$ & $13 / 29$ & $23 / 74$ & $20 / 48$ \\
\hline & Slow & $1.07(0.6 \mathrm{I}-1.88)$ & $3.00(1.52-5.93)$ & $1.40(0.75-2.60)$ & $2.00(1.03-3.89)$ \\
\hline & cases/controls & $36 / 103$ & $26 / 28$ & $35 / 81$ & $29 / 50$ \\
\hline & & \multicolumn{2}{|c|}{$\begin{array}{c}p \text { for interaction } \dagger=0.17 \\
A P \ddagger=52 \%\end{array}$} & \multicolumn{2}{|c|}{$\begin{array}{c}p \text { for interaction }=0.97 \\
A P=8 \%\end{array}$} \\
\hline \multirow{5}{*}{ SULTIAI } & Arg/Arg & $I^{*}$ & I.53 (0.86-2.7I) & - & - \\
\hline & cases/controls & $35 / 122$ & $22 / 34$ & & \\
\hline & His carriers & $2.30(1.18-4.45)$ & $2.87(1.36-6.05)$ & - & - \\
\hline & cases/controls & $31 / 75$ & $17 / 23$ & & \\
\hline & & \multicolumn{2}{|c|}{$p$ for interaction $=0.70$} & & \\
\hline
\end{tabular}

$*$ Reference category; † By likelihood ratio test; $\ddagger$ Attributable Proportion due to biological interaction (see methods)

CYP2E1 ( ${ }^{*} 5 A$ or $* 6$ alleles) by alcohol drinking. In addition, our results confirm previous findings of gastric cancer risk to be increased by alcohol intake and family history for cancer $[27,28]$.

Several limitations should be taken into account in the interpretation of our results. Firstly, based on the prevalence of the analyzed genotypic variants in our population (Table 2), our study was powered to detect an OR of 2.0 for common polymorphisms (with a significance level of $5 \%$ ), however not for CYP2E1*5 allele carriers, CYP2E $1{ }^{*} 5 A$ or ${ }^{*} 6$ allele carriers and the homozygotes variants of SULT1A1, EPHX3 and EPHX4. The study's sample size limits the ability to explore the combined effects of the genotypes, or gene-environment interactions, which highlights the need to increase the sample size in order to confirm our results. However, when appropriately conducted, large and small studies should give, theoretically, the same results, with just a more precise effect measure estimate from the larger ones [29]. Secondly, as in all casecontrol studies information bias may exist, leading to biased ORs related to the gene-environment interaction results. Thirdly, data on Helicobacter pylori infection were not available in our population.

This is the first study conducted on an homogenous ethnic group who evaluated the effect on gastric cancer risk of several metabolic genes SNPs contemporarily, and the effect of their combination with tobacco and alcohol. One of the main source of confounding in the genetic association studies arises from population stratification, since the ethnicity itself may be related to a specific disease and to the allele frequencies as well [30,31]. Our study showed a significant association between GSTT1 null genotype and gastric cancer, which is in keeping with the results of a recent meta-analysis considering only high-quality papers [8]. Individuals who have the homozyogous deletion in GSTT1 have no enzyme activity, and thus are more susceptible to carcinogens such as benzo $[\alpha]$ pyrene-7,8-diol epoxide and smaller reactive hydrocarbons, such as ethylene oxide and diepoxybutane [8]. We also reported that individuals carriers of the SULT1A1 variant allele, who have limited detoxification capability of xeniobiotics through sulfonate conjugation, have an additional risk of gastric cancer if smokers.

To our knowledge, we reported for the first time a strong effect modification by alcohol of the association between CYP2E1*5A or ${ }^{*} 6$ alleles and gastric cancer, with an increased risk among ever-drinkers. Two previous studies $[32,33]$ reported no association between CYP2E $1 * 5 A$ or ${ }^{*} 6$ allele and gastric cancer, however no one of them stratified data according to alcohol habits. Additionally, one study evaluating the identical association among black South-African males showed an increased risk of oesophageal cancer among drinkers carrying the CYP2E1 $* 5 A$ or $* 6$ alleles [34]. CYP2E1 is a naturally ethanol-inducible enzyme that is mainly involved in the metabolic activation of $N$-nitrosamines present in tobacco smoke and some dietary compounds, for which a causative role in gastric carcinogenesis has been hypothesised [2], and in the metabolism of fatty acids and several halogenated and aromatic compounds [35]. Additionally, CYP2E1 plays a minor role in alcohol metabolism, through the oxidation of ethanol to acetaldehyde and 1-hydroxyacetyl radicals [35]. The $* 5 A$ or ${ }^{*} 6$ alleles of CYP2E1 is characterized by some studies in an increased gene expression [36], so that individuals carrying the unfavourable variant might be at higher risk of gastric cancer because of: i) hyper activation of $N$-nitrosamines in more reactive species, especially 
among drinkers since enzyme activity is induced by alcohol; ii) hyper production of reactive oxygen species and subsequent cell toxicity generated by ethanol metabolism among drinkers. We expected to gain similar results for CYP2E1 RsaI polymorphism, identically associated with increased enzyme activity, however the few subjects in the stratified analysis probably did not show it. Since these results, however, are based on very few subjects (only one case drinker bearing ${ }^{*} 5 \mathrm{~A}$ or ${ }^{*} 6$ alleles) they need to be confirmed by larger studies.

Among the main results of our study, we found that GSTT1 null genotype individuals contemporarily NAT2 slow acetylators have a strongly increased risk of gastric cancer, with a more than just the additive effect of the risks associated with each of the two inherited SNPs. N-acetylation is considered a major detoxification step for carcinogenic aromatic arylamines, while GSTT1 is involved in the detoxification of polycyclic aromatic hydrocarbons, so individuals with one or both depleted phase II enzyme activities might be particularly susceptible to gastric damage from carcinogens, which is supported by the finding of an additional risk for ever-smokers. We used the attributable proportion due to interaction as a measure to quantify the biological interaction between those combined SNPs and showed a strong interaction between them. Assuming that the relationships studied are causal and based on the definition of biological interaction among two component causes [25,37], our results suggest that $52 \%$ of gastric cancer cases among GSTT1 null individuals with combined NAT2 slow acetylator phenotype are caused through a mechanism in which both risk factors are biological dependent in the same disease process. In other words, since biological interaction among two causes occurs when the effect of one is dependent from the presence of the other, in the absence of either of the two components (GSTT1 null or NAT2 slow), than a substantial number of gastric cancer cases would not occur. Given that in our population $25 \%$ of cases had a combination of those unfavourable genotypes, this means that a non negligible proportion of gastric cancer cases would have never developed if those enzymatic activities were adequate.

\section{Conclusion}

This study suggests that in this Italian population, GSTT1, SULT1A1 and NAT2 polymorphisms may modulate an individual's susceptibility to gastric cancer, particularly when more than one unfavourable genotype is present and in combination with cigarette smoke. Additionally, we showed that individuals carrying the $* 5 A$ or $* 6$ alleles of CYP2E1 are at increased risk for gastric cancer in drinkers. Clearly, since our study is based on a limited number of cases, it is critical that larger prospective studies possibly based on a single ethnic group confirms our results.

\section{List of abbreviations used}

$\mathrm{AP}=$ attributable proportion; $\mathrm{CI}=$ Confidence Interval; $\mathrm{CYP}=$ Cytochrome P450; GST = glutathione S-transferase; $\mathrm{HWE}=$ Hardy-Weinberg Equilibrium; $\mathrm{mEH}=$ microsomal Epoxide Hydrolase; NAT $=\mathrm{N}$-acetyltransferase; $\mathrm{OR}=$ Odds Ratio; PCR = Polymerase Chain Reaction; RR = Risk Ratio or Rate Ratio; SULT $=$ Sulfotransferase .

\section{Competing interests}

The author(s) declare they have no competing interests.

\section{Authors' contributions}

All authors read and approved the final manuscript. SB and GR conceived the study and coordinated the research group; SB and FG performed the statistical analysis and drafted the manuscript; FAST and GLT participated in the data analysis; DA carried out the genotyping; CMVD helped to draft the manuscript; RP, SR, DDU and ALG enrolled the patients and interviewed all them.

\section{Acknowledgements}

We are grateful to Rosarita Amore for the blood samples processing, Angelo De Lauretis and Emma De Feo for the database management, and Wendy Morotti for the linguistic revision of the final manuscript. This study was financially supported by a grant from Catholic University of Sacred Heart (DI projects 2007).

\section{References}

I. Verdecchia A, Mariotto A, Gatta G, Bustamante-Teixeira MT, Ajiki W: Comparison of stomach cancer incidence and survival in four continents. Eur J Cancer 2003, 39:1603-1609.

2. Correa P, Schneider BG: Etiology of gastric cancer: what is new? Cancer Epidemiol Biomarkers Prev 2005, I 4: I865-1868.

3. Aoki M, Yamamoto K, Noshiro H, Sakai K, Yokota J, Kohno T, Tokino T, Ishida S, Ohyama S, Ninomiya I, Uesaka K, Kitajima M, Shimada S, Matsuno S, Yano M, Hiratsuka M, Sugimura H, Itoh F, Minamoto T, Maehara Y, Takenoshita S, Aikou T, Katai H, Yoshimura K, Takahashi T, Akagi K, Sairenji M, Yamamura Y, Sasazuki T: A full genome scan for gastric cancer. J Med Genet 2005, 42:83-7.

4. Gonzalez CA, Sala N, Capella G: Genetic susceptibility and gastric cancer risk. Int J Cancer 2002, 100:249-260.

5. Garte S, Gaspari L, Alexandrie AK, Ambrosone C, Autrup H, Autrup JL, Baranova H, Bathum L, Benhamou S, Boffetta P, Bouchardy C, Breskvar K, Brockmoller J, Cascorbi I, Clapper ML, Coutelle C, Daly A, Dell'Omo M, Dolzan V, Dresler CM, Fryer A, Haugen A, Hein DW, Hildesheim A, Hirvonen A, Hsieh LL, Ingelman-Sundberg M, Kalina I, Kang D, Kihara M, Kiyohara C, Kremers P, Lazarus P, Le Marchand L, Lechner MC, van Lieshout EMM, London S, Manni JJ, Maugard CM, Morita S, Nazar-Stewart V, Noda K, Oda Y, Parl FF, Pastorelli R, Persson I, Peters WHM, Rannug A, Rebbeck T, Risch A, Roelandt L, Romkes M, Ryberg D, Salagovic J, Schoket B, Seidegard J, Shields PG, Sim E, Sinnet D, Strange RC, Stücker I, Sugimura H, To-Figueras J, Vineis $\mathrm{P}, \mathrm{Yu}$ MC, Taioli E: Metabolic gene polymorphism frequencies in control populations. Cancer Epidemiol Biomarkers Prev 200I, I 0:1239-1248.

6. Boccia S, Persiani R, La Torre G, Rausei S, Arzani D, Gianfagna F, Romano-Spica V, D'Ugo D, Ricciardi G: Sulfotransferase I A I polymorphism and gastric cancer risk: a pilot case-control study. Cancer Lett 2005, 229:235-243.

7. La Torre G, Boccia S, Ricciardi G: Glutathione S-transferase MI status and gastric cancer risk: a meta-analysis. Cancer Lett 2005, 2 I 7:53-60.

8. Boccia S, La Torre G, Gianfagna F, Mannocci A, Ricciardi G: Metaanalysis of GSTTI and gastric cancer. Mutagenesis 2006, 3:1432-1435.

9. Martinez C, Martin F, Fernandez JM, Garcia-Martin E, Sastre J, DiazRubio M, Agundez JA, Ladero JM: Glutathione S-transferases mu 
I, theta I, pi I, alpha I and mu 3 genetic polymorphisms and the risk of colorectal and gastric cancers in humans. Pharmacogenomics 2006, 7:11-18.

10. Boccia S, La Torre G, Gianfagna F, Mannocci A, Ricciardi G: NAcetyltransferase 2 status and gastric cancer risk: a preliminary meta-analysis. Ital J Public Health 2005, 2:53-57.

II. Boccia S, De Lauretis A, Gianfagna F, van Dujin CM, Ricciardi G: Cytochrome p450 2E I 5'-flanking region polymorphism and its interaction with alcohol, tobacco and GSTs in gastric cancer susceptibility: a meta-analysis of the literature. Carcinogenesis 2007, 28:10I-6.

12. Jourenkova-Mironova N, Mitrunen K, Bouchardy C, Dayer P, Benhamou S, Hirvonen A: High-activity microsomal epoxide hydrolase genotypes and the risk of oral, pharynx, and larynx cancers. Cancer Res 2000, 60:534-536.

13. Taningher M, Malacarne D, Izzotti A, Ugolini D, Parodi S: Drug metabolism polymorphisms as modulators of cancer susceptibility. Mutat Res 1999, 436:227-261.

14. Suzuki S, Muroishi Y, Nakanishi I, Oda Y: Relationship between genetic polymorphisms of drug-metabolizing enzymes (CYPIAI, CYP2EI, GSTMI, and NAT2), drinking habits, histological subtypes, and $p 53$ gene point mutations in Japanese patients with gastric cancer. J Gastroenterol 2004, 39:220-230.

15. Agudo A, Sala N, Pera G, Capella G, Berenguer A, Garcia N, Palli D, Boeing H, Del Giudice G, Saieva C, Carneiro F, Berrino F, Sacerdote C, Tumino R, Panico S, Berglund G, Siman H, Stenling R, Hallmans G, Martinez C, Amiano P, Barricarte A, Navarro C, Quiros JR, Allen N, Key T, Bingham S, Khaw KT, Linseisen J, Nagel G, Overvad K, Tjonneland A, Olsen A, Bueno-de-Mesquita HB, Boshuizen HC, Peeters $\mathrm{PH}$, Numans ME, Clavel-Chapelon F, Boutron-Ruault MC, Trichopoulou A, Lund E, Blaker H, Jenab M, Ferrari P, Norat T, Riboli E, Gonzalez CA: No association between polymorphisms in CYP2EI, GSTMI, NATI, NAT2 and the risk of gastric adenocarcinoma in the European prospective investigation into cancer and nutrition. Cancer Epidemiol Biomarkers Prev 2006, 15:1043-1045.

16. Boccia S, Gianfagna F, Persiani R, La Greca A, Arzani D, Rausei S, D'Ugo D, Magistrelli P, Villari P, van Duijn CM, Ricciardi G: Methylenetetrahydrofolate reductase C677T and AI298C polymorphisms and susceptibility to gastric adenocarcinoma in an Italian population. Biomarkers 2007, I 2:635-644.

17. Lauren P: The two histological main types of gastric carcinoma: diffuse and so-called intestinal-type carcinoma. An attempt at a histo-clinical classification. Acta Pathol Microbiol Scand 1965, 64:31-49.

18. Sobin LH, Wittekind C: TNM classification of malignant tumors, UICC. New York: Wiley-Liss; 2002.

19. Arand M, Muhlbauer R, Hengstler J, Jager E, Fuchs J, Winkler L, Oesch F: A multiplex polymerase chain reaction protocol for the simultaneous analysis of the glutathione S-transferase GSTMI and GSTTI polymorphisms. Anal Biochem 1996, 236: 184-186.

20. Coughtrie MW, Gilissen RA, Shek B, Strange RC, Fryer AA, Jones PW, Bamber DE: Phenol sulphotransferase SULTIAI polymorphism: molecular diagnosis and allele frequencies in Caucasian and African populations. Biochem J 1999, 337:45-49.

21. Sarmanova J, Tynkova L, Susova S, Gut I, Soucek P: Geneticpolymorphisms of biotransformation enzymes: allele frequencies in thepopulation of the Czech Republic. Pharmacogenetics 2000, 10:78I-788

22. Peluso M, Airoldi L, Armelle M, Martone T, Coda R, Malaveille $C$, Giacomelli G, Terrone C, Casetta G, Vineis P: White blood cell DNA adducts, smoking, and NAT2 and GSTMI genotypes in bladder cancer: a case-control study. Cancer Epidemiol Biomarkers Prev 1998, 7:34I-346.

23. Hung RJ, Boffetta P, Brennan P, Malaveille C, Hautefeuille A, Donato F, Gelatti U, Spaliviero M, Placidi D, Carta A, Scotto di Carlo A, Porru S: GST, NAT, SULTIAI, CYPIBI genetic polymorphisms, interactions with environmental exposures and bladder cancer risk in a high-risk population. Int I Cancer 2004, I I 0:598-604.

24. Smith CA, Harrison DJ: Association between polymorphism in gene for microsomal epoxide hydrolase and susceptibility to emphysema. Lancet 1997, 350:630-633.

25. Rothman KJ: Measuring interactions. In Epidemiology: an introduction Edited by: Rothman KJ. New York: Oxford University press; 2002:168-90.
26. Andersson T, Alfredsson L, Kallberg H, Zdravkovic S, Ahlbom A: Calculating measures of biological interaction. Eur J Epidemiol 2005, 20:575-579.

27. Bagnardi V, Blangiardo M, La Vecchia C, Corrao G: A meta-analysis of alcohol drinking and cancer risk. Br J Cancer 200I, 85: 1700-1705.

28. Lynch HT, Grady W, Suriano G, Huntsman D: Gastric cancer: new genetic developments. J Surg Oncol 2005, 90: I | 4-33.

29. Ioannidis JPA: Meta-analysis in public health: potential and problems. Ital J Public Health 2006, 3:9-I4.

30. Agudo A, Sala N, Pera G, Capella G, Berenguer A, Garcia N, Palli D, Boeing H, Del Giudice G, Saieva C, Carneiro F, Berrino F, Sacerdote C, Tumino R, Panico S, Berglund G, Siman H, Stenling R, Hallmans G, Marti nez C, Bilbao R, Barricarte A, Navarro C, Quiros JR, Allen N, Key T, Bingham S, Khaw KT, Linseisen J, Nagel G, Overvad K, Tjonneland A, Olsen A, Bueno-de-Mesquita HB, Boshuizen HC, Peeters $\mathrm{PH}$, Numans ME, Clavel-Chapelon F, Boutron-Ruault MC, Trichopoulou A, Lund E, Offerhaus J, Jenab M, Ferrari P, Norat T, Riboli E, Gonzalez CA: Polymorphisms in metabolic genes related to tobacco smoke and the risk of gastric cancer in the European prospective investigation into cancer and nutrition. Cancer Epidemiol Biomarkers Prev 2006, I5:2427-34.

31. Cordell HJ, Clayton DG: Genetic association studies. Lancet 2005, 366:|||2|-||3|.

32. Wu MS, Chen CJ, Lin MT, Wang HP, Shun CT, Sheu JC, Lin JT: Genetic polymorphisms of cytochrome p450 2EI, glutathione S-transferase $\mathrm{MI}$ and $\mathrm{TI}$, and susceptibility to gastric carcinoma in Taiwan. Int J Colorectal Dis 2002, 17:338-343.

33. Park GT, Lee OY, Kwon SY, Lee CG, Yoon BC, Hahm JS, Lee MH, Hoo Lee D, Kee CS, Sun HS: Analysis of CYP2EI polymorphism for the determination of genetic susceptibility to gastric cancer in Koreans. J Gastroenterol Hepatol 2003, 18:1257-I263.

34. Li D, Dandara C, Parker Ml: Association of cytochrome P450 2EI genetic polymorphisms with squamous cell carcinoma of the oesophagus. Clin Chem Lab Med 2005, 43(4):370-375.

35. Cederbaum Al: CYP2EI: biochemical and toxicological aspects and role in alcohol-induced liver injury. Mt Sinai J Med 2006, 73(4):657-672.

36. Uematsu F, Ikawa S, Kikuchi H, Sagami I, Kanamaru R, Abe T, Satoh $\mathrm{K}$, Motomiya M, Watanabe M: Restriction fragment length polymorphism of the human CYP2EI (cytochrome P450IIEI) gene and susceptibility to lung cancer: possible relevance to low smoking exposure. Pharmacogenetics 1994, 4(2):58-63.

37. Rothman KJ, Greenland S: Causation and causal inference in epidemiology. Am J Public Health 2005, 95:SI 44-I 50.

\section{Pre-publication history}

The pre-publication history for this paper can be accessed here:

http://www.biomedcentral.com/1471-2407/7/206/pre pub

Publish with Biomed Central and every scientist can read your work free of charge

"BioMed Central will be the most significant development for disseminating the results of biomedical research in our lifetime."

Sir Paul Nurse, Cancer Research UK

Your research papers will be:

- available free of charge to the entire biomedical community

- peer reviewed and published immediately upon acceptance

- cited in PubMed and archived on PubMed Central

- yours - you keep the copyright 